\title{
Proliferation in the normal cervix and in preinvasive cervical lesions
}

\author{
S Payne, N M Kernohan, F Walker
}

\begin{abstract}
Aims-To characterise further the proliferative compartment of the normal cervix and to document its alteration, if any, in the various grades of cervical intraepithelial neoplasia (CIN), particularly changes to the basal epithelial layer; to hypothesise as to the diagnostic and biological significance of any observed differences.

Method-Proliferative compartments from 86 cervical biopsy specimens (10 normal, 11 with koilocytic change only, 12 CIN I, nine CIN II, and 44 CIN III) were determined using microwave antigen retrieval and a standard three-step Streptavidin biotin peroxidase immunocytochemical technique incorporating the MIB-1 monoclonal antibody (directed against the Ki-67 antigen). Immunoreactivity was assessed as occupying either the lower one third, lower two thirds or all three thirds of the squamous epithelium. Basal cell positivity was also quantitated. Results-Specimens without CIN showed a thin suprabasal proliferative compartment two to four cells thick. True basal positivity was infrequent. With increasing grade of CIN, the growth compartment stretched evermore superficially so that in lesions of CIN III almost the full thickness of epithelium was cycling. In all grades of CIN, basal cell proliferation was significantly increased.
\end{abstract}

Conclusions-In normal cervix, the parabasal layers represent the main proliferative pool with the basal layer providing a reserve. When CIN supervenes, this proliferative compartment expands commensurate with the grade of dysplasia and as basal turnover is increased specifically the intimate relation between epithelium and basement membrane might be disturbed, facilitating invasion. The diagnostic utility of these changes in growth compartments is limited.

( $F$ Clin Pathol 1996;49:667-671)

Keywords: cervix uteri, cell proliferation, cervical intraepithelial neoplasia.

Department of Pathology, University Medical Buildings, Foresterhill,

Aberdeen AB9 2ZD

Correspondence to: Dr S Payne.

Accepted for publication 4 June 1996 is well recognised that the prolife h) rate of tumours frequently exce that of their normal tissue counterparts and govern biological aggressiveness. $M$ activity both increased in frequency and abnormal in position serves as one of the stringent criteria for the histological diagnosis of cervical intraepithelial neoplasia (CIN). ${ }^{1}$ This suggests that in these preinvasive lesions, proliferative changes may be occurring.

The recent ability to define cycling cells using conventional immunocytochemistry is a significant technical advance. Proliferating cell nuclear antigen (PCNA) ${ }^{2}$ and the $\mathrm{Ki}-67$ antigen ${ }^{3}$ have both found widespread application to this end, but especially with the advent of microwave antigen retrieval, ${ }^{4}$ the latter "may be a more robust marker of cell proliferation" 5 especially as the former has a half-life sufficiently long to survive in cells recently exiting the cell cycle. Present throughout the cell cycle, except in the resting $G_{0}$ phase, ${ }^{6}$ assessments of $\mathrm{Ki}-67$ staining have excellent correlation with the results of thymidine incorporation studies. ${ }^{7}$ The objectives of the present study were:

(1) to determine the growth compartment of the normal cervix;

(2) to define the growth compartment in the respective grades of cervical intraepithelial neoplasia;

(3) to hypothesise as to the diagnostic and biological significance of differences in the proliferation compartments between the two groups (normal and CIN).

\section{Methods}

Eighty six consecutive cervical biopsy specimens taken during colposcopy as a result of cytologically detected abnormality were fixed in $10 \%$ neutral buffered formalin for at least 12 and often 24 hours before standard processing. Histological grade was assessed on haematoxylin and eosin stained sections using standardised criteria ${ }^{1}$ by one of us (SP). Where grading was marginal, it was assigned by consensus over a double-headed microscope (SP and NMK). Additional sections were mounted on aminopropyltriethoxysilane (APES; A1345; Sigma, Poole, Dorset, UK) coated slides and. subjected to immunohistochemical analysis for the $\mathrm{Ki}-67$ antigen.

\section{IMMUNOCYTOCHEMISTRY}

Standard three-step Streptavidin biotin complex immunocytochemistry was performed on sections which had undergone microwave antigen retrieval while buffered in 0.01 molar citrate solution (BDH, Poole, Dorset, UK; 10081). Optimised retrieval time was 20 minutes in a Proline standard microwave oven set at maximal output of $850 \mathrm{~W} \cdot{ }^{8}$ The MIB-1 antibody directed against the $\mathrm{Ki}-67$ antigen (Immunotech, Marseille, France; 0505) was used at a dilution of 1 in 150 in TBS (0.005 M Tris $/ \mathrm{HCl} ; 0.015 \mathrm{M} \mathrm{NaCl}, \mathrm{pH}$ 7.6). Each 
Table 1 Distribution of Ki-67 staining according to histological grade

\begin{tabular}{llllll}
\hline \multirow{2}{*}{$\begin{array}{l}\text { Distribution of Ki-67 } \\
\text { staining }\end{array}$} & \multicolumn{5}{l}{ Histological grade } \\
\cline { 2 - 6 } & Normal & Koilocytosis & CIN I & CIN II & CIN III \\
\hline Lower third alone & 10 & 11 & 11 & 2 & 1 \\
Lower and middle thirds & 0 & 0 & 1 & 3 & 11 \\
All three thirds & 0 & 0 & 0 & 4 & 32
\end{tabular}

Results are expressed as number of cases.

experimental run was controlled with a rectal adenocarcinoma serving as a positive control and tissue receiving diluent alone (TBS) as a negative control.

Non-specific isotype interactions were ruled out by use of an irrelevant antibody of similar

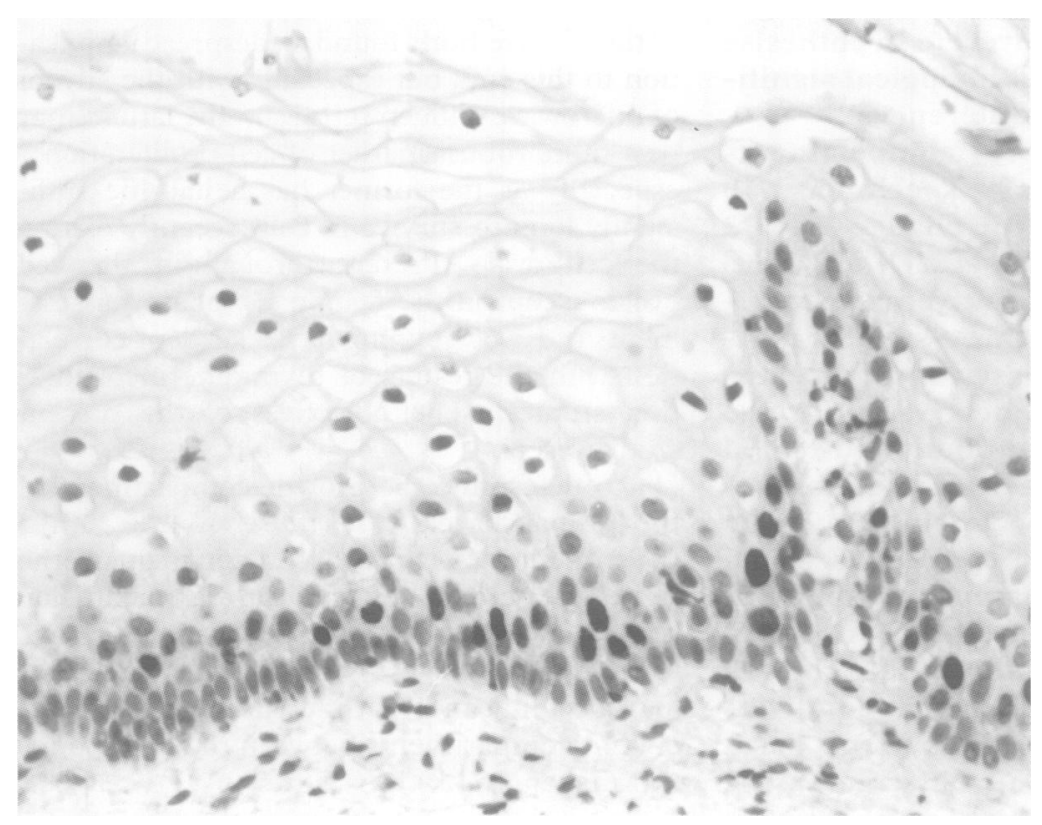

Figure 1 MIB-1 staining in a normal cervical biopsy specimen.

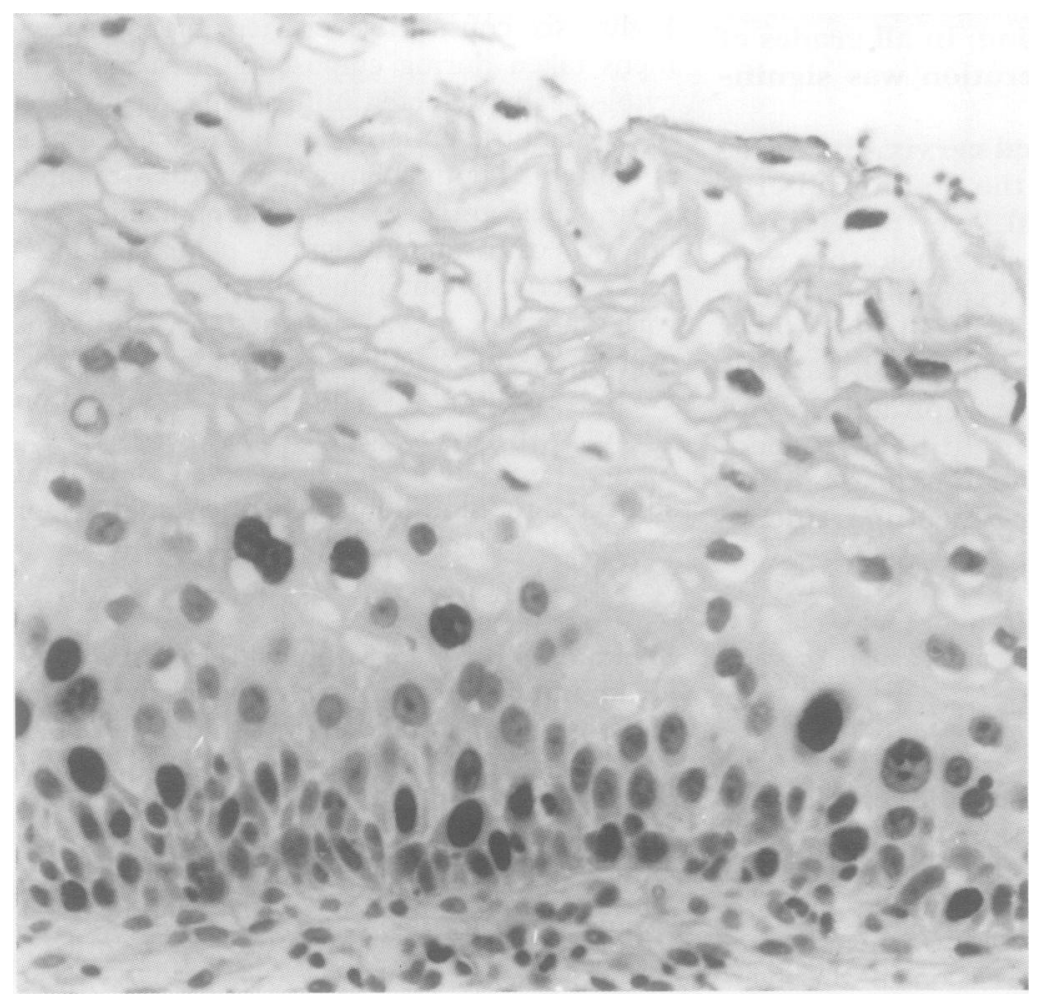

Figure 2 A case of CIN I. Staining is restricted to the lower third, basal cells are positive and koilocytes negative. isotype to MIB-1 (IgG1; CD19 (Dako, High Wycombe, UK)) as a further control.

ASSESSMENT OF PROLIFERATION

In accord with the histological criteria for grading CIN, the distribution of $\mathrm{Ki}-67$ positiv- $\bar{\Xi}$ ity in any dysplastic focus was described as $\square$ occupying either the lower third, lower and $\frac{0}{5}$ middle thirds or all three thirds of the full epi- 으․ thelial face including those thirds uninvolved $\underset{\vec{D}}{\vec{P}}$ by disease. To exclude cutting into or out of $\frac{\text { T }}{0}$ small zones of CIN, an equivalent grade of dysplasia to the haematoxylin and eosin $\overline{\frac{D}{D}}$ stained section was confirmed in the test and $\vec{\Phi}$ control slide from each case.

A quantitative assessment of basal cell $\mathrm{Ki}-67$ के positivity was undertaken using a simple $\vec{\circ}$ counting technique. From informative areas, $\overrightarrow{\vec{\omega}}$ 400 consecutive basal cells were evaluated at $\times 400$ and the percentage immunoreactive (the $\frac{\overline{0}}{0}$ labelling index) calculated. Where tissue artefact, inflammation or very focal dysplasia $\infty$ precluded examining this number, as many as $\mathscr{g}$ possible within the lesional cervix were as-

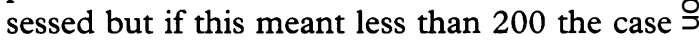
was deemed to have had "unsatisfactory" $\vec{\longrightarrow}$ immunocytochemistry and excluded.

\section{STATISTICS}

To test the hypothesis that differences in the mean number of $\mathrm{Ki}-67$ positive basal cells existed between normal cervixes, those involved by koilocytosis alone and the various grades of intraepithelial neoplasia, the un- $\bar{\partial}$ paired Mann-Whitney Test was applied and $\mathrm{p} \stackrel{0}{\circ}$ values $<0.05$ were taken as statistically $\Omega$ significant.

\section{Results}

A histological grade and staining distribution of $\mathrm{Ki}-67$ could be assigned to all 86 cases (table 궁 1). For seven specimens it was impossible to assess 200 or more basal cells and their "unsatisfactory" immunocytochemistry was excluded $\delta$ leaving 79 entrants to this arm of the study. $₹$ Control slides gave expected staining and vali-음 dated experimental procedures.

\section{BIOPSY SPECIMENS FROM NON-NEOPLASTIC} EPITHELIA

Ten biopsy specimens were assigned the grade $N$ normal and displayed either no abnormality or $\mathrm{\omega}_{\mathrm{W}}$ merely physiological variants of normalo (chronic inflammation, metaplasia around theo transformation zone or atrophy). In all 10 , MIB-1 staining was limited to the lower third of the ectocervix or transitional zone (fig 1). $\frac{T}{0}$ Usually, it comprised a layer two to four cells $\frac{\vec{D}}{\mathrm{D}}$ thick in the immediate suprabasal region.

No glandular abnormalities were seen in this $\varrho$ series. Endocervical cells were infrequently and focally positive, as were occasional stromal 8 cells. Both immature and mature squamous metaplasia possessed a solely parabasal stain-⿳亠丷厂 ing pattern.

Eleven cases were categorised as showing koilocytosis and displayed characteristic viral changes. Nuclear variability amounting to CIN I was specifically excluded. Each showed Ki-67 staining restricted to the parabasal zone much as with normal cases. 
Table 2 Basal Ki-67 labelling indexes in the various histological grades

\begin{tabular}{llllll}
\hline & Normal & Koilocytosis & CIN I & CIN II & CIN III \\
\hline Number of cases "satisfactory" & 10 & 9 & 11 & 7 & 42 \\
Mean labelling index (SD) (\%) & $3.2(5.1)$ & $9.9(12)$ & $22.1(12.4) \dagger$ & $22.9(8.6)^{\star} \dagger$ & $28.6(15.0)^{\star} \dagger$ \\
Range labelling index (\%) & $0.0-14.9$ & $0.5-38.1$ & $7.2-39.6$ & $11.0-33.9$ & $7.2-69.9$ \\
\hline
\end{tabular}

${ }^{\star} \mathrm{p}<0.05$ when compared with normal group.

tp $<0.05$ when compared with koilocytic group.

BIOPSY SPECIMENS FROM PREINVASIVE LESIONS Twelve biopsy specimens were diagnosed as CIN I. In 11, MIB-1 staining was confined to the lower third but, in comparison with normal or koilocytic groups, was less regular, with peaking and troughing of a slightly thickened immunoreactive layer (fig 2). One case had

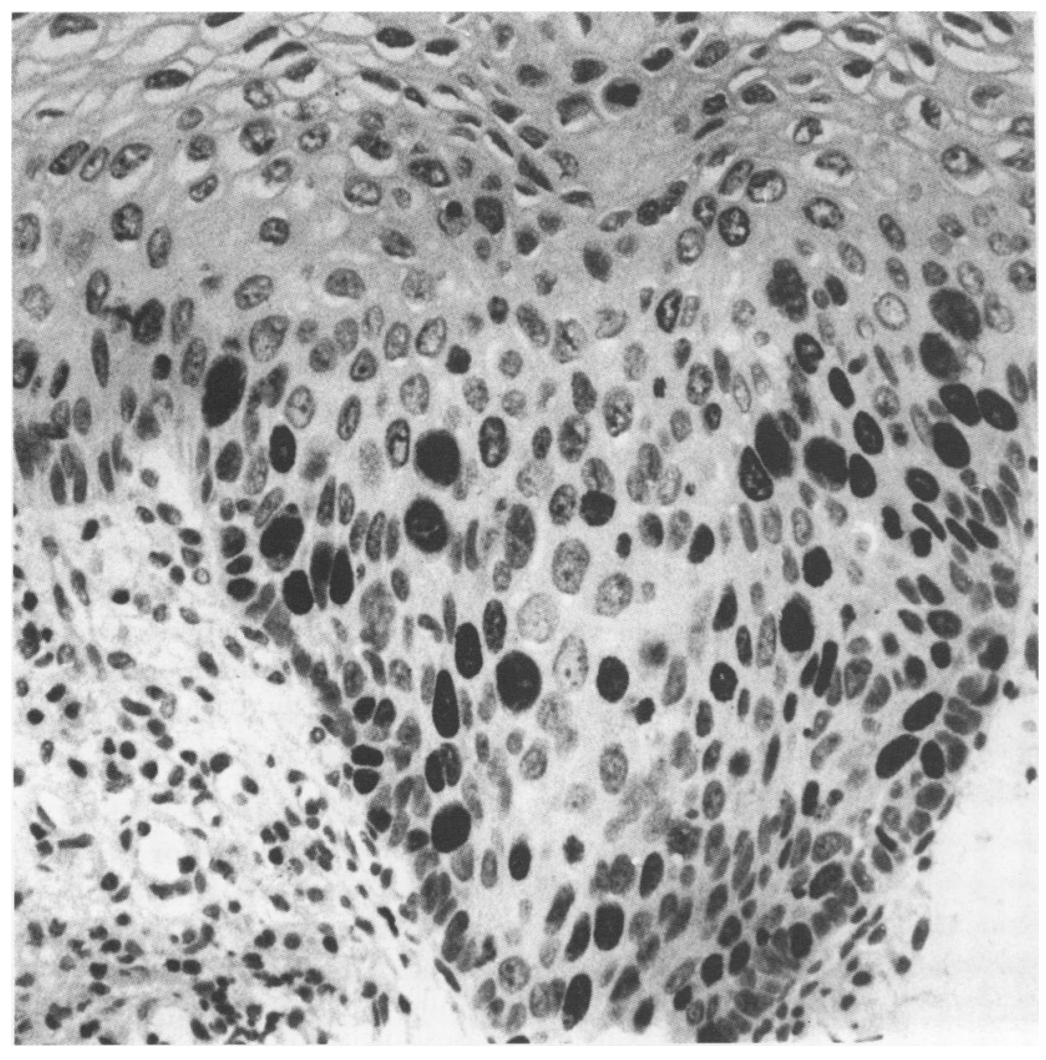

Figure 3 A case of CIN II. Staining can be seen in the lower and middle thirds and koilocytes are again negative.

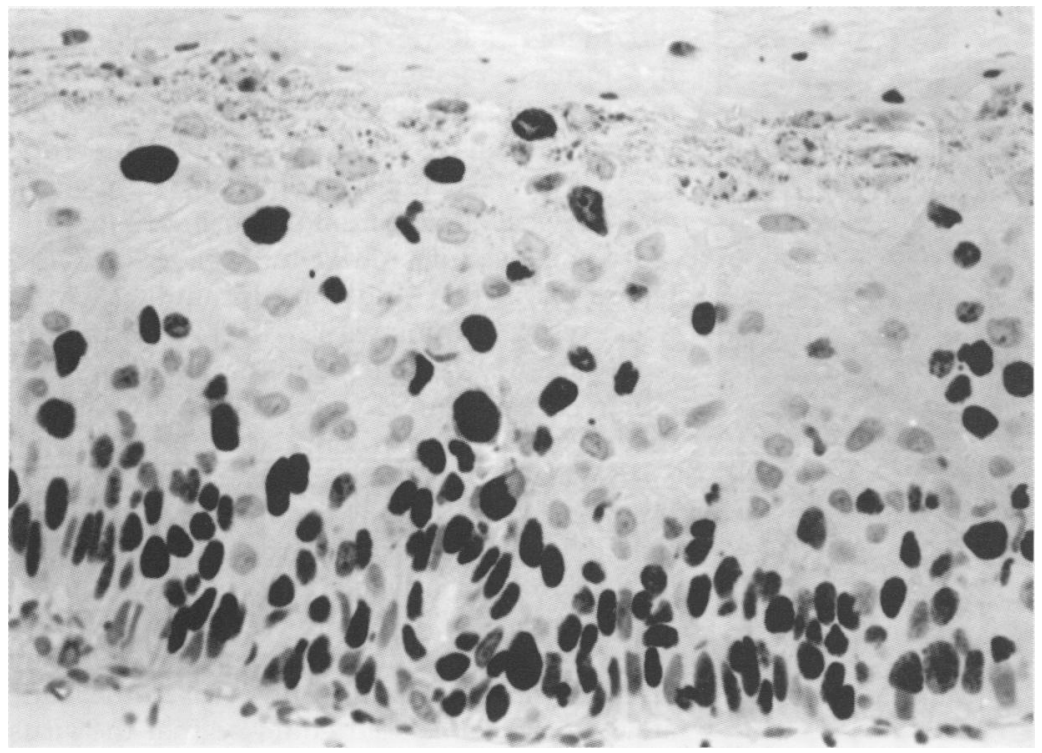

Figure 4 A case of CIN III. All three thirds of the epithelial face are positivity and basal cell labelling is increased.
Ki-67 positivity which occupied both lower and middle thirds

The grade CIN II was assigned to nine cases. In two, MIB-1 was restricted to the lower third of the epithelium, in four both the lower and middle thirds were involved (figs 2 and 3 ) and in three staining stretched into all three thirds. Conventional or aberrant mitotic figures stained but koilocytes in this and other groups were negative (figs 2 and 3 ).

Forty four cases showed CIN III. In the majority (32 cases) Ki-67 immunoreactivity occupied the lower, middle and upper thirds of the epithelium (fig 4) but in some (11 cases) only the lower and middle compartments were stained. The density of positivity was increased in this group with most cells in abnormal areas staining. Dysplastic areas were sharply defined from neighbouring normal epithelium-the so-called Schiller Line (fig 5). Despite extension into the upper third, often a thin layer, approximately two cells thick, abutting onto the free surface was MIB-1 negative but occasionally staining was truly full-thickness. Contrary to the established trend, a single case of CIN III had Ki-67 limited to the lower third (fig 6).

BASAL CELL STAINING WITH THE MIB-1 ANTIBODY The results of basal $\mathrm{Ki}-67$ positivity against histological grade are shown in table 2 . In normal biopsy specimens, basal staining was observed in occasional isolated cells spaced at around 30-40 cells apart. Squamous metaplasia in the transformation zone minimally increased this percentage.

Koilocytic specimens showed increased basal $\mathrm{Ki}-67$ labelling which just failed to reach statistical significance when compared with normal controls. In contrast, cases with CIN, irrespective of grade, all showed statistically significant augmentation in their basal cycling compartment when compared with both normal and koilocytic cases. Mean labelling indexes (CIN I, 22.1; CIN II, 22.9; CIN III, 28.6) suggested approximately one in four basal cells was turning over although in five cases of CIN, more than $50 \%$ of basal cells reacted with MIB-1. No difference between the various $C I N$ grades was detected.

\section{Discussion}

Using a reliable and sensitive immunocytochemical technique incorporating a well defined monoclonal antibody, MIB-1, directed against a marker of proliferation, $\mathrm{Ki}-67$, this work has attempted to define the cycling compartment of normal ectocervix and to define how this is altered in CIN.

The recurrent pattern in normal biopsy specimens was of a linear suprabasal layer of 
cycling cells, two to four cells thick, with only occasional immunoreactive basal cells. Using tritiated thymidine incorporation, a previous study ${ }^{9}$ reported identical findings. It has been suggested that this arrangement whereby parabasal cells contribute in excess of $90 \%$ of the proliferative activity means that the basal layer exists as a reserve for the major parabasal proliferative pool and in itself contributes little. ${ }^{10}$ The exact composition of this normal cycling compartment seems to vary with the phase of menstrual cycle. ${ }^{1}$

When CIN supervenes, $\mathrm{Ki}-67$ immunoreactivity expands commensurate with the CIN grade. Two recent studies, one using PCNA, ${ }^{12}$

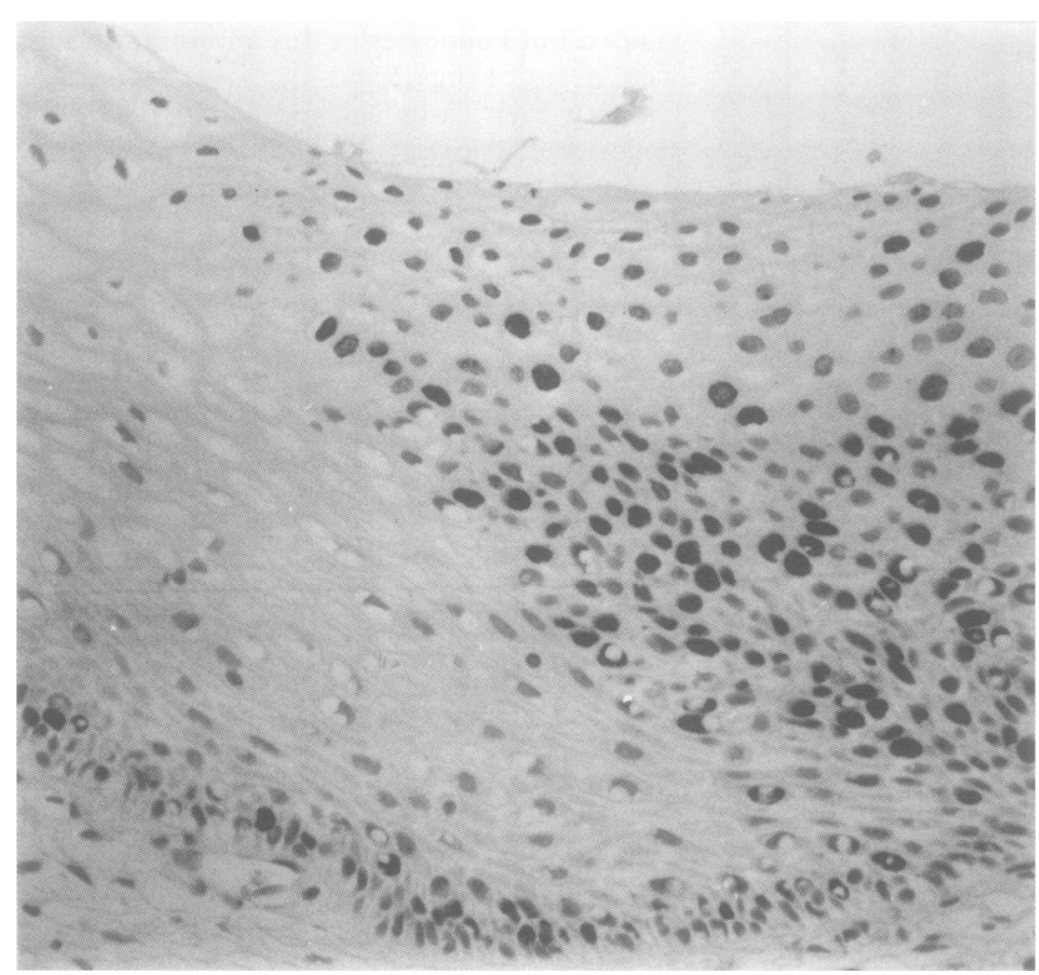

Figure 5 A case of CIN III. The sharp transition between normal and dysplastic epithelium defines the Schiller Line.

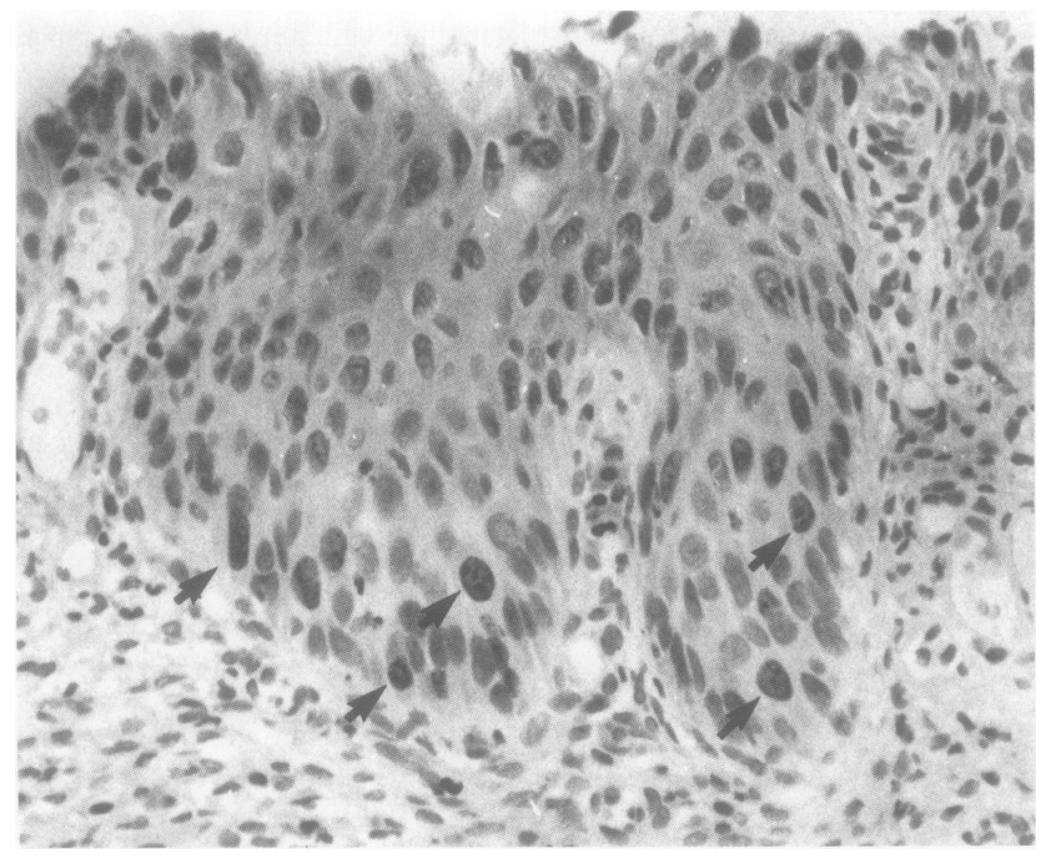

Figure 6 A case of CIN III. Staining is restricted to occasional basal and parabasal cells. the other using $\mathrm{Ki}-67,{ }^{13}$ describe similar observations in series of selected benign, metaplastic and preinvasive biopsy specimens. It is of note that many cases of CIN III showed a thin, non- $c$ staining layer just below the free surface. This $\varrho$ suggests a degree of terminal differentiation, with escape from the cell cycle in the most superficial epithelia.

The consistent observation of increased basal immunoreactivity in preinvasive lesions $\underset{\vec{S}}{\vec{P}}$ may be more biologically important. Despite음 aberrant cycling predisposing to the acquisi- 흘 tion of "additional hits" in the oncogenic proc- $\frac{\bar{D}}{\vec{D}}$ ess, the ultimate fate of suprabasal dysplastic $\stackrel{\triangle}{\varrho}$ epithelia is to be shed and lost at the surface. In contrast, the intimate relation between basal $\overrightarrow{0}$ cells and the underlying basement membrane might be disturbed by abnormal turnover and $\vec{\omega}$ may facilitate invasive growth. In accord with $\frac{\Omega}{8}$ this concept, Mittal et $a l^{14}$ have correlated? quantitatively increasing basal MIB-1 positivity with increasing grade of CIN but only in a small study incorporating 13 dysplastic lesions. Potentially, unusually high basal proliferation 0 could explain isolated cases becoming rapidly progressive soon after minimally aberrant or $\square$ normal morphological assessment. ${ }^{15}$ A study of the prognostic significance of various degrees $\stackrel{5}{\oplus}$ of basal cell cycling in each of the categories of $\overrightarrow{0}$ CIN would be justified although clearly any therapeutic manoeuvre or indeed even sample $\square$ collection $^{16}$ may alter the natural history of $\sum^{O}$ such lesions. These observations suggest that $\frac{\partial}{\partial}$ the screening of cervical smears may represent the evaluation of an epiphenomenon as the $\mathbb{D}$ unsampled, variably cycling basal layer may $\overrightarrow{\vec{A}}$ solely hold the key to the ultimate aggressiveness of cervical dysplastic lesions.

That cases were identified which failed to conform to the established trend (for example, a case of CIN III with MIB-1 positivity:restricted to the lower third (fig 6)) may limit 3 . the diagnostic utility of $\mathrm{Ki}-67$ in this situation. Boon et $a l^{12}$ similarly felt it inappropriate to classify CIN cases solely on the basis of PCNA을 staining or to distinguish reliably CIN II from $D$ CIN III lesions. However, other authors ${ }^{17}$ 을. believe that the technique may help to differentiate a low grade squamous lesion from its mimics, including metaplasia and post- 0 menopausal atrophy. Similarly, tuboendometrial metaplasia has been reliably differentiated from adenocarcinoma in situ and 0 endocervical adenocarcinoma using $\mathrm{Ki}-67 .{ }^{18} \overparen{\mathbb{D}}$

Irrespective of underlying grade of $\mathrm{CIN}$, koilocytes in this study and in another ${ }^{17}$ were negative on staining with MIB-1. This finding $\overrightarrow{\mathbb{D}}$ is in accord with conventional wisdom that $\frac{}{\mathbb{D}}$ either the replicative cycle of human papillo- $\frac{2}{0}$ mavirus (HPV) can only be supported by terminally differentiated, non-cycling cells of 0 the upper strata or that productive HPV infection may disable normal replicative machin- $\frac{\hat{O}}{7}$ ery. ${ }^{19}$ However, Demeter et $a l^{20}$ observed $\stackrel{ }{\rightleftharpoons}$ PCNA positive koilocytes and hypothesised that viral gene products, particularly E7, may re-establish replication in otherwise differentiated superficial cells. It could be that the virus indeed induces PCNA, an accessory protein for DNA polymerase $\delta$, ${ }^{5}$ but this alone is inad- 
equate for true re-entry into the cell cycle where $\mathrm{Ki}-67$ would be expressed.

This study has detailed the expansion of the proliferative compartment of the cervix in lesions of CIN. It could be extended to evaluate the application of MIB-1 to diagnostic cervical cytology where, because of the superficial nature of the cervical scrape, the absence of $\mathrm{Ki}-67$ positive cells would suggest that the proliferative compartment was parabasal and nonexpanded and would argue against the presence of a high grade intraepithelial lesion.

We are indebted to Mrs Anne MacMillan and Irene Watson for typing this manuscript, to Mr George King for helpful technical advice, and to Dr Neil Langlois for his assistance with the statistical analysis. SP was supported by a Research Fellowship from the Scottish Home and Health Department.

1 Wright TC, Kurman RJ, Ferenczy A. Precancerous lesions of the cervix. In: Kurman RJ, ed. Blaustein's pathology of the female genital tract. New York: Springer Verlag, 1994:22978.

2 Hall PA, Levison DA, Woods AL, Yu CCW, Kellock DB, Watkins JA, et al. Proliferating cell nuclear antigen (PCNA) immunolocalisation in paraffin sections: an index of cell proliferation with evidence of deregulated expresof cell proliferation with evidence of deregulated

3 Brown DC, Gatter KC. Monoclonal antibody Ki-67: Its use in histopathology. Histopathology 1990;1 7:489-503.

4 Cattoretti G, Pileri S, Parravicini C, Becker MGH, Poggi S, Bifulco C, et al. Antigen unmasking on formalin-fixed, paraffin-embedded tissue sections. F Pathol 1993;171:8398 .

5 Yu CC, Filipe IM. Update on proliferation-associated antibodies to formalin-fixed paraffin-embedded tissue and their clinical applications. Histochem $\mathcal{F} 1993 ; 25: 843-53$.

6 Gerdes J, Lemke H, Baisch H, Wacker H-H, Schwab U, Stein H. Cell cycle analysis of a cell proliferationassociated human nuclear antigen defined by the monoclonal antibody Ki-67. F Immunol 1984;133:1710-15.

7 Kamel OW, Franklin WA, Ringus JC, Meyer JS. Thymidine labelling index and $\mathrm{Ki}-67$ growth fraction in lesions of the breast. Am F Pathol 1989;134:107-13.
8 Shi S-R, Key ME, Kalra KA. Antigen retrieval in formalinfixed, paraffin-embedded tissues: an enhancement method for immunohistochemical staining based on microwave oven heating of tissue sections. F Histochem Cytochem 1991;39:741-8.

9 Schellhas HF, Heath C. Cell renewal in the human cervix uteri: A radioautographic study of DNA, RND and protein synthesis. Am f Obstet Gynecol 1969;104:617-32.

10 Averette $\mathrm{HE}$, Weinstein CD, Frost P. Autoradiographic analysis of cell proliferation kinetics in human genital tissues. Am f Obstet Gynecol 1970;108:8-17.

11 Konishi I, Fujii S, Nonogaki H, Nanbu Y, Iwai T, Mori T. Immunohistochemical analysis of estrogen receptors, progesterone receptors, $\mathrm{Ki}-67$ antigen, and human papillomavirus DNA in normal and neoplastic epithelium of the uterine cervix. Cancer 1991;68:1340-50.

12 Boon ME, Luzzatto R, Beck S, Bosch MMG, Hermans J, Rietveld WJ. Proliferation profile of benign and premalignant cervical epithelium as established by the PCNA nant cervical epithelium as established by the

13 Al-Saleh W, Delvenne P, Greimers R, Fridman V, Doyen J, Boniver J. Assessment of $\mathrm{Ki}-67$ antigen immunostaining in squamous intraepithelial lesions of the uterine cervix Correlation with the histologic grade and human papillomavirus type. Am f Clin Pathol 1995;104:154-60.

14 Mittal KR, Demopoulas RI, Goswami S. Proliferating cell nuclear antigen (cyclin) expression in normal and abnormal cervical squamous epithelia. Am $\mathcal{f}$ Surg Pathol 19903;17:117-22.

15 Berkeley AS, Livolsi VA, Schwartz P. Advanced squamous cell carcinoma of the cervix with recent normal papanicolau tests. Lancet 1980;ii:375-6.

16 Buxton EJ, Luesley DM, Shafi MI, Rollason M. Colposcopically directed punch biopsy: a potentially misleading investigation. Br f Obstet Gynaecol 1991;98:1273-6.

17 McCluggage WG, Buhidma $M$, Tang L, Maxwell $P$, Bharucha H. Monoclonal antibody MIB-1 in the assessment of cervical squamous epithelial lesions [abstract]. $\mathcal{F}$ Pathol 1995;176(Suppl):46A.

18 McCluggage WG, Maxwell P, McBride HA, Hamilton PW, Bharucha $\mathrm{H}$. Monoclonal antibodies $\mathrm{Ki}-67$ and MIB-1 in the distinction of tuboendometrial metaplasia from endocervical adenocarcinoma and adenocarcinoma in situ in formalin-fixed materiel. Int f Gynecol Pathol 1995; 14:209-16.

19 Taichmann LB, Reilly SS, Laporta RF. The role of keratinocyte differentiation in the expression of epitheliotropic viruses. F Invest Dermatol 1983;81 (Suppl 1):1375-405.

20 Demeter LM, Stoler MH, Broker TR, Chow LT. Induction of proliferating cell nuclear antigen in differentiated keratinocytes of human-papillomavirus-infected lesions. Hum Pathol 1994;25:343-8. 